\title{
Pressure- and Temperature-Dependent Crystallization Kinetics of Isotactic Polypropylene under Process Relevant Conditions
}

\author{
Yvonne Spoerer ${ }^{1,2}$, Regine Boldt ${ }^{3}\left(\mathbb{D}\right.$, René Androsch ${ }^{4}$ and Ines Kuehnert ${ }^{1, *(D)}$ \\ 1 Institute of Polymer Materials, Department of Processing Technology, Leibniz-Institut für Polymerforschung \\ Dresden e. V., Hohe Str. 6, 01069 Dresden, Germany; spoerer@ipfdd.de \\ 2 Dutch Polymer Institute (DPI), P.O. Box 902, 5600 AX Eindhoven, The Netherlands \\ 3 Institute of Polymer Materials, Department of Materials Engineering, Leibniz-Institut für Polymerforschung \\ Dresden e. V., Hohe Str. 6, 01069 Dresden, Germany; boldt@ipfdd.de \\ 4 Interdisciplinary Center for Transfer-oriented Research in Natural Sciences, Martin Luther University, \\ Halle-Wittenberg, 06099 Halle/Saale, Germany; rene.androsch@iw.uni-halle.de \\ * Correspondence: kuehnert@ipfdd.de
}

check for updates

Citation: Spoerer, Y.; Boldt, R.; Androsch, R.; Kuehnert, I. Pressureand Temperature-Dependent Crystallization Kinetics of Isotactic Polypropylene under Process Relevant Conditions. Crystals 2021, 11, 1138. https://doi.org/10.3390/ cryst11091138

Academic Editors: Jun Xu, Rufina G. Alamo and Günter Reiter

Received: 25 August 2021

Accepted: 15 September 2021

Published: 18 September 2021

Publisher's Note: MDPI stays neutral with regard to jurisdictional claims in published maps and institutional affiliations.

Copyright: (C) 2021 by the authors. Licensee MDPI, Basel, Switzerland. This article is an open access article distributed under the terms and conditions of the Creative Commons Attribution (CC BY) license (https:/ / creativecommons.org/licenses/by/ $4.0 /)$.

\begin{abstract}
In this study, a non-nucleated homopolymer (HP) and random copolymer (RACO), as well as a nucleated HP and heterophasic copolymer (HECO) were investigated regarding their crystallization kinetics. Using pvT-measurements and fast scanning chip calorimetry (FSC), the crystallization behavior was analyzed as a function of pressure, cooling rate and temperature. It is shown that pressure and cooling rate have an opposite influence on the crystallization temperature of the materials. Furthermore, the addition of nucleating agents to the material has a significant effect on the maximum cooling rate at which the formation of $\alpha$-crystals is still possible. The non-nucleated $\mathrm{HP}$ and RACO materials show significant differences that can be related to the sterically hindering effect of the comonomer units of RACO on crystallization, while the nucleated materials HP and HECO show similar crystallization kinetics despite their different structures. The pressure-dependent shift factor of the crystallization temperature is independent of the material. The results contribute to the description of the relationship between the crystallization kinetics of the material and the process parameters influencing the injection-molding induced morphology. This is required to realize process control in injection molding in order to produce pre-defined morphologies and to design material properties.
\end{abstract}

Keywords: polypropylene; crystallization kinetic; fast scanning chip calorimetry; pvT-behavior

\section{Introduction}

Isotactic polypropylene (iPP) is a polymorphic, semi-crystalline thermoplastic. It can crystallize into $\alpha-, \beta-$, or $\gamma$-modification, as well as form a mesophase depending on the crystallization conditions. If the material is processed by injection molding, the macromolecules are exposed to high thermo-mechanical forces, which vary according to the processing conditions (temperature, pressure, velocity, mold geometry). As a result of these forces, the crystallization process including the final supermolecular structure of the molded part is influenced, and with this the mechanical properties. The morphology of iPP has been studied since the 1960s [1-3]. Natta et al. [3] described the structure and arrangement of the macromolecules within the monoclinic $\alpha$-modification as a result of slow or moderate cooling. Further investigations focused on the thermal influence on the crystalline symmetry of the $\alpha$-modification [4] and described the formation of a maximum ordered monoclinic $\alpha_{2}$-modification under high crystallization temperatures or as a result of high-temperature annealing. The supermolecular structure of the monoclinic phase is described as spherulitic, in which the lamellae are arranged both radially and tangentially to the spherulite radius. The $\beta$-modification is described as a pseudo-hexagonal structure, which is formed by crystallization from the quiescent, supercooled melt and the presence 
of special nucleating agents $[2,5,6]$. The $\gamma$-structure is orthorhombic and preferably formed as a result of presence of chain defects limiting the length of isotactic sequences, in lower molecular weight fractions, or under pressure [7]. An intermediate ordered structure is a mesophase, which is described as a metastable (at ambient temperature) and disordered phase that forms when the melt cools rapidly. Details of the iPP mesophase, including the structure, morphology and properties, are reported in the literature [8-10].

The influence of the molar mass distribution and stereoregularity of iPP homopolymers (HPs) on the morphology, tailored using different catalyst systems, was investigated by Gahleitner et al. [11]. The investigations showed that metallocene-catalyst based grades with a narrow molar mass distribution exhibit a significantly higher nucleation density $N$ and reduced growth rate $G$. For both metallocene and Ziegler-Natta catalyzed systems, it was concluded that retarded growth of the $\alpha$-modification favors the development of the $\gamma$-modification. Further investigations were undertaken on the influence of the incorporation of comonomers into the macromolecular chain (random copolymers, RACOs) on the crystallization kinetics [12-16]. 1-Alkene co-units act as a defect in the chain, thus hindering crystal growth. This leads not only to a reduced crystallinity but also to special effects on the crystal modification. For example, an increase in the $\gamma$-modification was found with increasing ethylene co-unit content. To investigate the influence of the comonomer content on the crystallinity, propylene-ethylene random copolymers with different ethylene contents were investigated [12]. The investigations showed that with increasing ethylene content from 0 to $4.9 \mathrm{wt} \%$ both crystallinity and growth rate decrease. A further group of iPP copolymers are the heterophasic copolymers (HECO's) which consist of an iPP matrix and rubbery particles made from random ethylene-propylene copolymers (EPC or EPR). Investigations [10,17-19] showed that the crystallization kinetics of the iPP matrix is influenced by the EPC content as well as the composition of the EPC particles. For example, isothermal crystallization experiments at temperatures between $120{ }^{\circ} \mathrm{C}$ and $130{ }^{\circ} \mathrm{C}$ [17] on $\mathrm{iPP} / \mathrm{EPR}$ blends with an EPR content of up to $70 \mathrm{wt} \%$ and a propylene content of 49 and $70 \mathrm{wt} \%$ showed a lower growth rate and nucleation density compared to the iPP homopolymer. Studies on the influence of EPC content on crystallization of PP/EPC blends by Doshev et al. [18] showed that the crystallinity $X_{C}$ and the growth rate of the iPP matrix pass through a maximum at an average EPC content of about $50 \mathrm{wt} \%$. At ethylene contents $\geq 50 \mathrm{wt} \%$, separate crystallization of the iPP matrix and EPC particles was observed at temperatures of $120^{\circ} \mathrm{C}$. The investigations where undertaken with differential scanning calorimetry (DSC) at cooling rates of $5 \mathrm{~K} / \mathrm{min}$.

In recent years, the crystallization kinetics of the aforementioned materials has been investigated under high cooling rates [10,20-24], that is, under process-related conditions. All investigations indicated that the temperature-dependence of the crystallization rate often is bimodal depending on the nucleation mechanism. Heterogeneous nucleation takes place under low cooling conditions, favoring formation of $\alpha$-crystals. In contrast, homogeneous nucleation takes place under high cooling conditions, which favor the formation of the mesophase. De Santis et al. [23,24] investigated the cooling rate-related crystallization of a non-nucleated iPP homopolymer under cooling rates ranging from 15 to $1000 \mathrm{~K} / \mathrm{s}$. They concluded that at cooling rates up to $90 \mathrm{~K} / \mathrm{s}$ the investigated material forms the $\alpha$-monoclinic crystalline phase. At cooling rates between 90 and $150 \mathrm{~K} / \mathrm{s}$, the $\alpha$-phase content decreased on expense of formation of a mesophase at about $40{ }^{\circ} \mathrm{C}$. At cooling rates above $150 \mathrm{~K} / \mathrm{s}$, only the formation of the mesophase was detected. At cooling rates above $1000 \mathrm{~K} / \mathrm{s}$, finally, the crystallization of the material was suppressed when cooling to below the glass transition temperature. Studies [20,25] on the influence of presence of 1-alkene co-units in random copolymers on the cooling rate-dependent crystallization behavior indicated that the incorporation of 1-alkenes into the iPP chain results in a reduction of the crystallization rate and crystallinity. It seems proven that with increasing chain length of the 1-alkene co-units, the crystallization is increasingly hindered. Thus, investigations [26] on RACOs based on different co-units, showed a bimodal relationship between the rate of ordering and the crystallization temperature and, therefore, they follow similar laws as the 
iPP homopolymers. Furthermore, it was shown that the formation of both the monoclinic $\alpha$-phase and the mesophase is slower for the RACOs. The rate of phase transformation decreases with the content of the co-units. The incorporation of 1-alkene co-units seems to have a stronger effect on the crystallization of the $\alpha$-phase than on that of the mesophase. The authors assume that the differences in molecular orientation are due to different contents of co-units in the crystalline and mesophase. Recent studies on the effect of EPC particle concentration and composition on the crystallization behavior of HECOs $[10,27]$ showed that the introduction of ethylene-rich random ethylene-propylene copolymers results in an additional nucleation effect.

Further studies focused on the effect of pressure on the crystallization [28-32]. Investigations by Assmussen [33,34] showed that the compressibility decreases with the degree of branching of the polymers due to the hindered crystallization. Investigations by Drongelen et al. [29] on iPP homopolymers at pressures of 5 and $25 \mathrm{MPa}$ and cooling rates of 0.1 to $2.0 \mathrm{~K} / \mathrm{s}$ showed that the formation of $\alpha$ - and $\gamma$-phases always occurs combined with the $\gamma$-phase being formed preferentially at high pressures and decreasing cooling rates, as also described elsewhere $[31,35,36]$. In summary, for the formation of the crystalline phase in iPP, this means that the mesophase is preferentially formed at high cooling rates and low pressures, the $\alpha$-phase at low cooling rates and low pressure, and the $\gamma$-phase at low cooling rates and high pressure. All phases can form in combination according to the process history.

The literature review revealed that many investigations were undertaken in the field of crystallization under process-relevant conditions. However, it was also found that studies were only undertaken on a certain material grade and/or only under certain conditions (temperature-dependent or pressure-dependent). A comprehensive investigation of the crystallization kinetics of different material grades, both temperature- and pressuredependent, is not available yet. In this project, four different commercially available iPP grades were investigated. The materials were examined by means of fast scanning chip calorimetry (FSC) and pvT-analysis under process-related conditions for their cooling rate-related and pressure-dependent crystallization behavior. The results were evaluated according to the following criteria: non-isothermal crystallization temperature as function of pressure, cooling rate, and isothermal crystallization as a function of temperature/supercooling.

\section{Materials and Methods}

\subsection{Materials}

In this study, four different iPP grades from Borealis AG, Braskem Europe GmbH and Sabic were analyzed. All grades are designed for injection molding. The materials differ in terms of their macromolecular structure, with material data given in Table 1. The data were taken from the specifications of the supplier; own measurements were labeled by a star symbol (*). The RACO has an ethylene content of $3 \mathrm{wt} \%$.

Table 1. Material properties. MFR (melt flow rate) $-230{ }^{\circ} \mathrm{C} / 2.16 \mathrm{~kg}, \mathrm{~T}_{\text {melt }}$-DSC (differential scanning calorimetry), $10 \mathrm{~K} / \mathrm{min}$, * own measurement. (HP-homopolymer, RACO—random copolymer, HECO—heterophasic copolymer).

\begin{tabular}{ccccccc}
\hline Material & Grade & Density $\left[\mathbf{g} / \mathbf{c m}^{\mathbf{3}}\right]$ & $\begin{array}{c}\text { Nucleated } \\
\text { Yes/No }\end{array}$ & MFR $[\mathbf{g} / \mathbf{1 0}$ min] & Yield Stress $[\mathbf{M P a}]$ & $\mathbf{T}_{\text {melt }}{ }^{*}\left[{ }^{\circ} \mathbf{C}\right]$ \\
\hline iPP-1 & HP & 0.900 & no & 19 & n.s. & 163 \\
iPP-2 & HP & 0.905 & yes & 20 & 40 & 166 \\
iPP-3 & RACO & 0.900 & no & 23 & 15 & 150 \\
iPP-4 & HECO & 0.905 & yes & 15 & 26 & 164 \\
\hline
\end{tabular}

\subsection{Differential Scanning Calorimetry (DSC)}

The DSC investigations on crystallization and melting behavior were performed with a Q1000 device (TA Instruments, New Castle, DE, USA). For this purpose, samples of about $5 \mathrm{mg}$ were weighed into an aluminum pan. The program was carried out according to the 
heating-cooling-heating method in a temperature interval from $-80{ }^{\circ} \mathrm{C}$ to $210{ }^{\circ} \mathrm{C}$ at heating and cooling rates of $10 \mathrm{~K} / \mathrm{min}$. For this purpose, the material was first heated to $210^{\circ} \mathrm{C}$ at a rate of $10 \mathrm{~K} / \mathrm{min}$ and equilibrated for $5 \mathrm{~min}$ to delete the thermal history. Afterwards, the sample was cooled to $-80{ }^{\circ} \mathrm{C}$ at a rate of $10 \mathrm{~K} / \mathrm{min}$ and then reheated to $210{ }^{\circ} \mathrm{C}$ at the same rate. During the measurement, nitrogen was applied with a flow rate of $50 \mathrm{~mL} / \mathrm{min}$ to avoid oxidative degradation.

\subsection{Fast Scanning Chip Calorimetry (FSC)}

The isothermal crystallization behavior and the cooling rate-dependent crystallization temperature were investigated by FSC. The respective programs are shown schematically in Figure 1. The FSC analysis was carried out with the Flash DSC 1 (Mettler-Toledo GmbH, Greifensee, Switzerland) [37]. For the measurement, a sample of a few 10 to $100 \mathrm{ng}$ was placed on a Mettler-Toledo MultiStar UFS 1 chip sensor. The sample was first heated to $200{ }^{\circ} \mathrm{C}$ and equilibrated. To prevent thermal degradation, the sample was purged with nitrogen during the measurements. Afterwards, for isothermal investigations, the sample was cooled down to temperatures between $0{ }^{\circ} \mathrm{C}$ and $130{ }^{\circ} \mathrm{C}$ with a cooling rate of $1000 \mathrm{~K} / \mathrm{s}$ to avoid crystallization during cooling. The sample was then kept at the respective temperature for $5 \mathrm{~s}$ and allowed to crystallize. After each isothermal crystallization step, the sample was cooled down to $-80{ }^{\circ} \mathrm{C}$, heated again to $200{ }^{\circ} \mathrm{C}$, for erasing the thermal history, and cooled to the next crystallization temperature. The crystallization peak time was determined from the plotted heat flow of the isothermal FSC measurement as a function of time. The crystallization peak time describes the time at the peak maximum. To determine the cooling rate-dependent crystallization, the sample was cooled from $200{ }^{\circ} \mathrm{C}$ to $-80^{\circ} \mathrm{C}$ at different cooling rates in the range of 10 to $2000 \mathrm{~K} / \mathrm{s}$. Microscopic images were taken of the isothermally and cooling rate-dependent crystallized samples by means of a polarized-light optical microscope (Kern and Sohn GmbH, Bahlingen, Germany), operated in reflection mode.

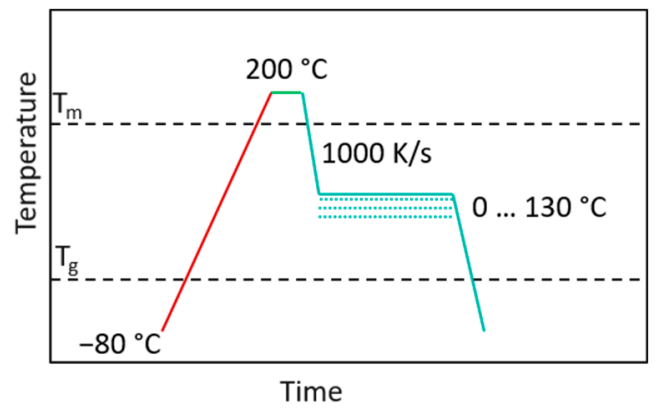

(a)

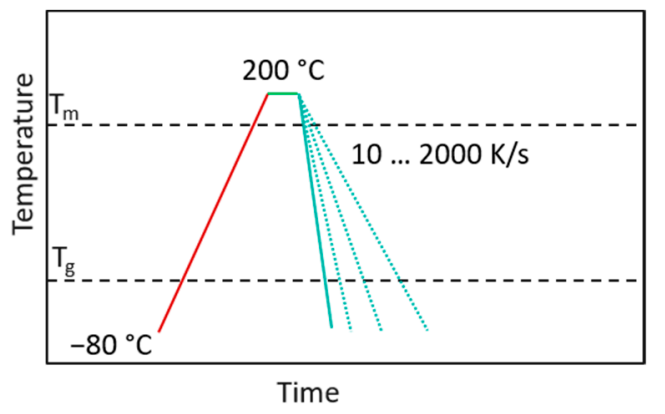

(b)

Figure 1. Scheme of the used method for isothermal (a) and non-isothermal (b) fast scanning chip calorimetry (FSC) measurement.

\subsection{Pressure-Volume-Temperature Measurement (pvT)}

The specific volume (v) as function of pressure (p) and temperature $(T)$ and the pressure-dependent crystallization temperature were analyzed by the use of a PVT500 device (GÖTTFERT Werkstoff-Prüfmaschinen $\mathrm{GmbH}$, Buchen, Germany). The sample was melted in a channel at $200{ }^{\circ} \mathrm{C}$ for $5 \mathrm{~min}$ to delete the thermal history. Purging the sample with nitrogen was not possible, but was also not mandatory, since the sample was covered by placing a piston directly on the sample surface during the entire measurement. Afterwards, the pvT-behavior was analyzed at isobaric condition in a temperature interval from $220^{\circ} \mathrm{C}$ to $40{ }^{\circ} \mathrm{C}$, at different pressures ranging from $20 \mathrm{MPa}$ to $120 \mathrm{MPa}$. The sample was cooled with air at a rate of about $7 \mathrm{~K} / \mathrm{min}$. The crystallization temperature was determined at the intersection of the slopes fitted on the specific volume in the melt state 
and during crystallization, as reported in the literature [31,38]. The samples showed no signs of thermal degradation (color change) after removal.

\section{Results and Discussion}

\subsection{Crystallization Temperature as Function of Pressure}

Figure 2 shows the pvT curves of the 4 materials at pressures from 20 to $120 \mathrm{MPa}$. Based on the curves, conclusions can be drawn about the crystallization temperature, causing a significant decrease of specific volume. The curves show the typical sigmodal shape at all pressures which is indicating the phase transition from melt to crystals. After reaching the crystallization temperature $T_{C}$, the material crystallizes and the specific volume decreases significantly. As expected from literature, $T_{C}$ shifts to higher temperatures with increasing pressure $[31,32,39,40]$. It is known that the influence of pressure on $T_{C}$ is linear, where the pressure shift factor is determined as the slope by fitting the curves (Figure 3). A comparison of the pressure shift factor reported in the literature and calculated from experimental data is given in Table 2. They are in agreement with the literature and the shift factor is independent of the macromolecular structure. Zuidema et al. [32] concluded that due to the linear shift of the pressure-dependent transition temperature the crystal growth rate is shifted in the same way. Comparison of the materials, provided in Figure 3, shows that the pressure-dependent crystallization temperature corresponds to the following tendency: iPP- $1<$ iPP- $3<$ iPP- $2=$ iPP- 4 . Thus, the non-nucleated materials 1 and 3 crystallize at lower temperatures than the nucleated materials 2 and 4 .
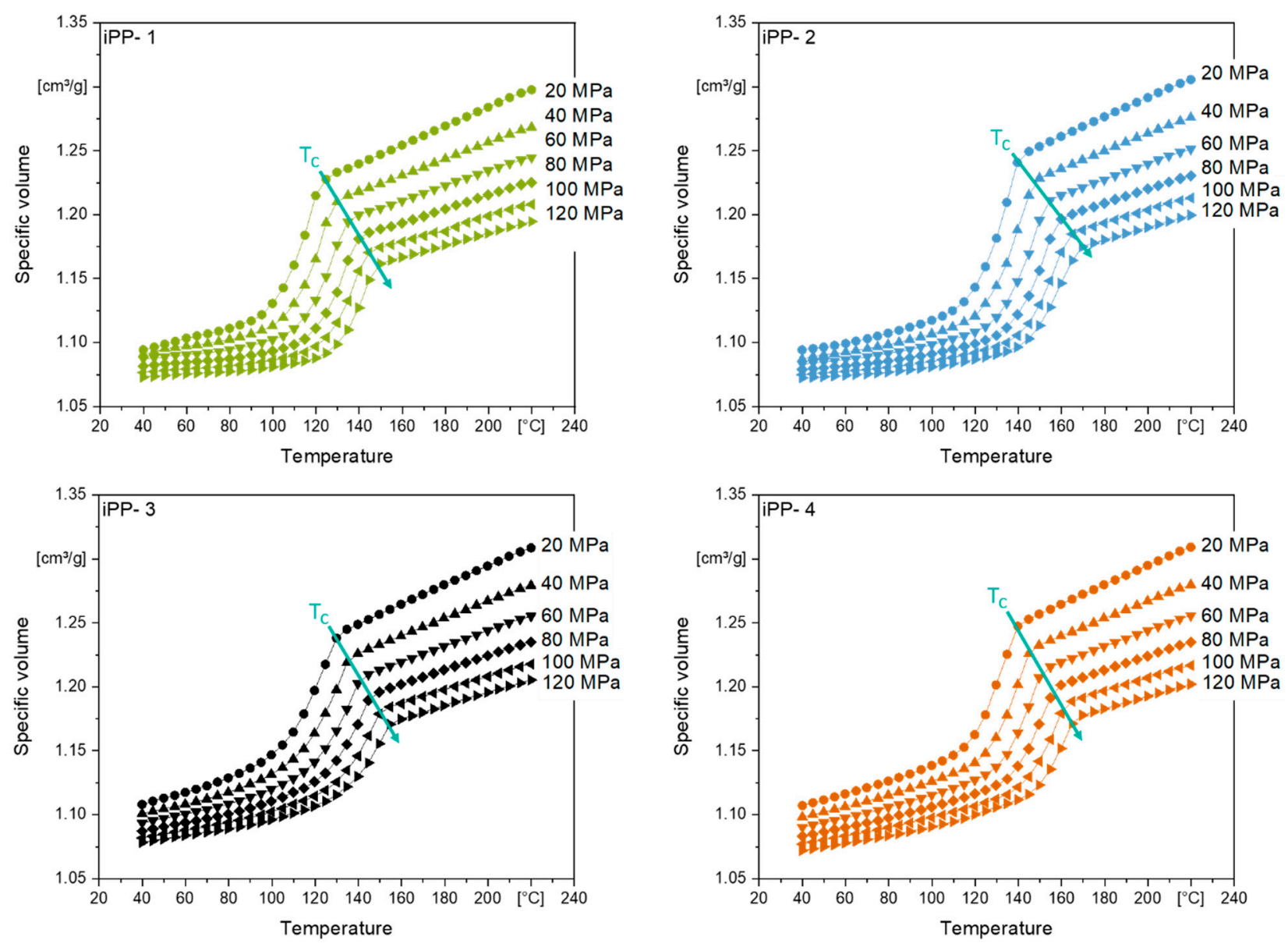

Figure 2. Isobaric pressure-volume-temperature (pvT) curves of the different iPP grades at different pressures. The cooling rate was about $7 \mathrm{~K} / \mathrm{min}$. 


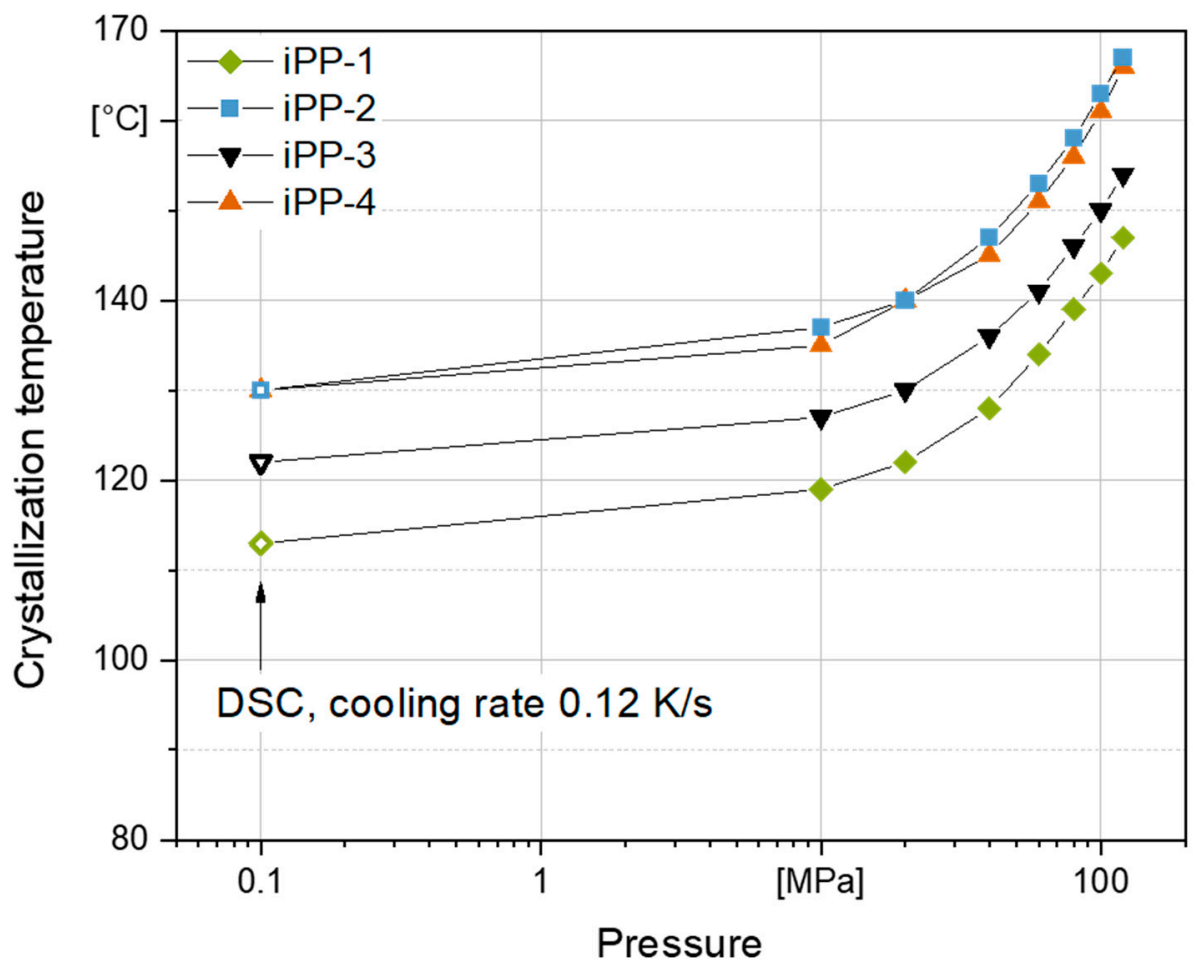

Figure 3. Pressure-dependent crystallization temperature determined from the pvT-curves.

Table 2. Linear pressure-dependent shift factor, dependent on molecular weight MW, polydispersity and cooling ratecomparison literature review and own investigations. (polydispersity is the quotient of the weight average $\bar{M}_{W}$ and the number average $\bar{M}_{n}$ of the molecular weight).

\begin{tabular}{|c|c|c|c|c|c|c|}
\hline & Material & $\bar{M}_{W}[\mathrm{~g} / \mathrm{mol}]$ & $\frac{\bar{M}_{W}}{\bar{M}_{n}}$ & Cooling Rate $[\mathrm{K} / \mathrm{s}]$ & Pressure Shift Factor [K/MPa] & R-Value \\
\hline iPP-1 & iPP HP & $238 \times 10^{3}$ & 2.1 & 0.11 & 0.25 & 0.996 \\
\hline iPP-2 & iPP HP & $260 \times 10^{3}$ & 3.2 & 0.11 & 0.27 & 0.996 \\
\hline iPP-3 & iPP RACO & $213 \times 10^{3}$ & 2.5 & 0.11 & 0.24 & 0.996 \\
\hline iPP-4 & iPP HECO & $238 \times 10^{3}$ & 2.6 & 0.11 & 0.27 & 0.997 \\
\hline \multicolumn{7}{|c|}{ Reference } \\
\hline [31] & iPP HP & $365 \times 10^{3}$ & 5.2 & - & 0.27 & - \\
\hline [39] & iPP HP & $300 \times 10^{3}$ & 6.4 & 0.042 & 0.2287 & - \\
\hline [41] & iPP HP & - & - & 0.083 & 0.2625 & - \\
\hline$[42]$ & iPP HP & - & - & 0.10 & 0.2536 & - \\
\hline [43] & iPP HP & \multicolumn{2}{|c|}{ different fractions } & 0.012 & 0.38 & - \\
\hline [32] & iPP HP & $365 \times 10^{3}$ & 5.4 & 40 & 0.5 & - \\
\hline
\end{tabular}

The coefficients of linear and volume expansion, $\alpha$ and $\beta$, were determined according to Equations (1) and (2) [33]:

$$
\begin{gathered}
\beta=\frac{1}{v}\left(\frac{d v}{d T}\right)_{p} \\
\alpha=\frac{1}{3} \beta
\end{gathered}
$$

Accordingly, $\beta$ at a given pressure was determined from the slope at each temperature and the corresponding value for the specific volume.

It is known that the coefficient of expansion of the melt is rather independent of temperature and decreases with increasing pressure [33]. In the crystallization temperature range, maximum values $\left(\alpha_{\max }\right)$ are present which are not based on the change in the 
molecular vibrations but are due to the volume decrease during crystallization. The HP iPP1 and iPP-2 show similar maximum $\alpha_{\max }$ values of $1.5 \times 10^{-3} 1 / \mathrm{K}$, so it seems that the nucleation of iPP-2 has no significant effect on the linear expansion, as expected. The maximum values for the copolymers iPP-3 $\left(1.1 \times 10^{-3} 1 / \mathrm{K}\right)$ and iPP-4 $\left(1.2 \times 10^{-3} 1 / \mathrm{K}\right)$ are lower than those of the HP iPP-1 and iPP-2. The reason for the difference is probably that in case of iPP-3 and iPP-4 crystallization is sterically hindered by the comonomer units. In the lower temperature range, the expansion coefficient is present without superimposed crystallization contraction, just as in the melt range. While $\alpha$ of all materials in the melt range is $1.6 \times 10^{-4} 1 / \mathrm{K}$, the $\alpha$-values (at T $=40^{\circ} \mathrm{C}$ ) for the HP iPP-1 and iPP-2 are 5 and $6 \times 10^{-5} 1 / \mathrm{K}$, respectively. For iPP-3 and iPP-4, the values are $1 \times 10^{-4} 1 / \mathrm{K}$. The higher linear expansion coefficients of the copolymers iPP-3 and iPP-4 are due to the higher content of amorphous phase, as can be assumed from [33].

\subsection{Crystallization Temperature as a Function of Cooling Rate}

Crystallization in processing, such as injection molding or extrusion, is generally non-isothermal and occurs under high cooling rates. Figure 4 shows the crystallization temperatures of the investigated materials as a function of the cooling rate. Referring to Figure 3 and 4, it can be seen that the pressure has an opposite effect on the crystallization temperature compared to the cooling rate, which means that the crystallization temperature decreases as the cooling rate increases. This effect was already discussed by van der Beek et al. [31]. Investigations on the crystallization kinetics of an iPP homopolymer were carried out at cooling rates from 0.1 to $35 \mathrm{~K} / \mathrm{s}$ and pressures from 20 to $60 \mathrm{MPa}$. The investigation revealed that the transition from the melt to the crystalline phase is becoming less distinct and widespread with increasing cooling rate at a certain pressure, due to the suppressed crystallization. In terms of pressure dependence, it is revealed that $T_{C}$ shifts to higher values due to the pressure dependence of the equilibrium melting temperature. However, the onset crystallization temperature is detected at the same undercooling for an identical thermal history and is, therefore, independent on pressure [31]. Comparison of the materials shows that the non-nucleated iPP-1 (HP) and iPP-3 (RACO) crystallize at lower temperatures than the nucleated iPP-2 (HP) and iPP-4 (HECO) at a given cooling rate. In the case of iPP-1, a second crystallization peak appeared at the low temperature level at a cooling rate of $50 \mathrm{~K} / \mathrm{s}$ suggesting that there is a replacement of $\alpha$-crystallization by mesophase formation, as already described in $[20,23,24,44]$. In the case of the non-nucleated RACO iPP-3, a second crystallization peak already appears at $30 \mathrm{~K} / \mathrm{s}$, which is due to a broadening of the $\alpha$-crystallization peak and suggests two different heterogeneous nucleation mechanisms, as discussed in [45]. Possible reasons for the different nucleation mechanism are non-random nucleation, or activation of additional heterogeneous nuclei, reported in [46]. The arrows in Figure 4 mark the maximum cooling rates at which mesophase/crystal formation is still possible. For iPP-1 and iPP-3, these cooling rates are 700 and $500 \mathrm{~K} / \mathrm{s}$, respectively. The nucleated iPP-2 and iPP-4 crystallize at higher temperatures, which allows them to crystallize even at cooling rates above $700 \mathrm{~K} / \mathrm{s}$. In both cases no replacement of $\alpha$-crystallization by mesophase formation was detected. In the case of the nucleated HECO iPP-4, a second heterophasic nucleation mechanism could be detected as in the case of the non-nucleated RACO iPP-3, but it appears only at higher cooling rates at around $1000 \mathrm{~K} / \mathrm{s}$ which is probably due to the EP-content [47]. The difference in crystallization behavior is also represented in the micrographs of Figure 5. The non-nucleated iPP-1 and iPP-3 samples show a lower nucleation density and larger spherulites than the nucleated iPP-2 and iPP-4. Looking at the material specific results, it can be seen that the nucleation density increases with the cooling rate. In the case of iPP-1, a distinct change is seen in the semi-crystalline structure cooled at $10 \mathrm{~K} / \mathrm{s}$ and $100 \mathrm{~K} / \mathrm{s}$. The structures after cooling with $100 \mathrm{~K} / \mathrm{s}$ are less pronounced, indicating the replacement of $\alpha$-crystals by the mesophase. It can be seen that crystallization of the non-nucleated iPP-1 and iPP-3 seems to be suppressed at cooling rates of about $1000 \mathrm{~K} / \mathrm{s}$, while in the case of 
nucleated iPP-2 and iPP-4, isolated crystalline structures are still visible at cooling rates of $1000 \mathrm{~K} / \mathrm{s}$.

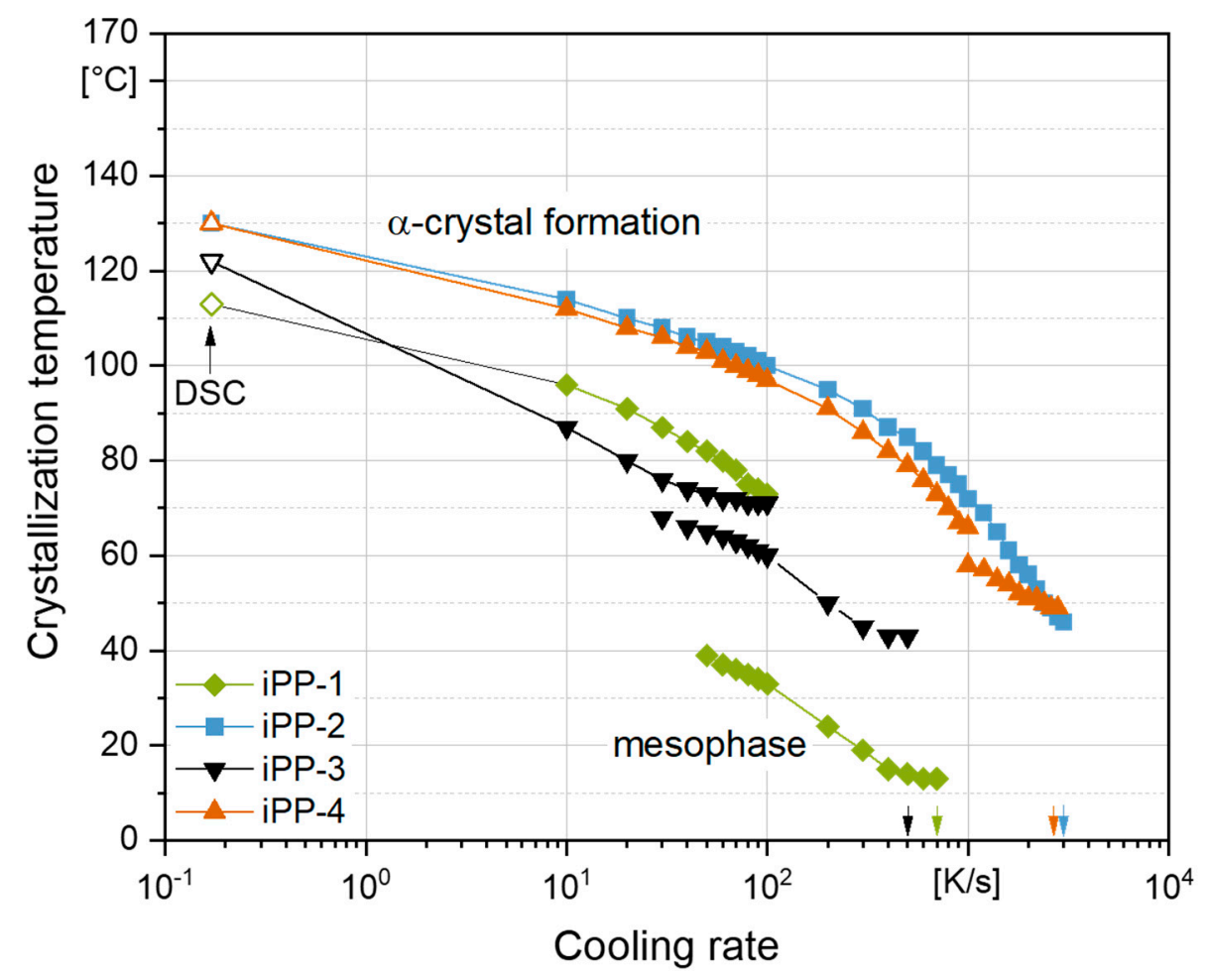

Figure 4. Crystallization temperature of the investigated iPP grades as function of the cooling rate.

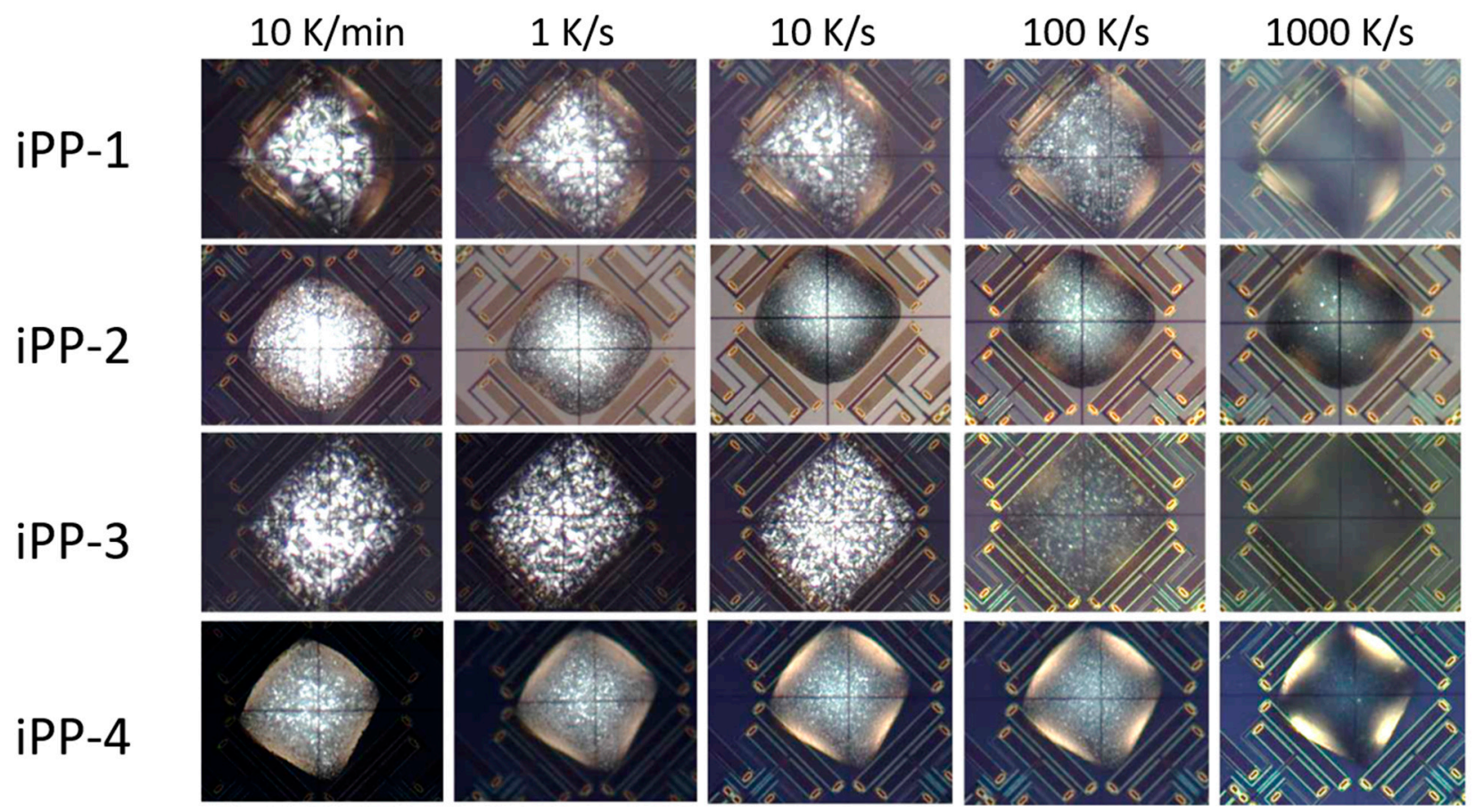

Figure 5. Comparison of the micrometer-scale structure of the investigated iPP grades, after cooling at different cooling rates, as indicated on top.

Figure 6 shows heating curves of the materials after they were crystallized at different cooling rates. The formation of the mesophase in the low temperature range of samples can 
be seen with the cold-crystallization peak, which varies between the materials depending on the thermal history. The bold curves indicate the minimum cooling rate necessary for the formation of the mesophase or of crystals during heating. For non-nucleated grades (iPP-1 and iPP-3), the minimum cooling rate for mesophase formation is $300 \mathrm{~K} / \mathrm{s}$. For the nucleated grades (iPP-2 and iPP-4), these are $1800 \mathrm{~K} / \mathrm{s}$ and $1000 \mathrm{~K} / \mathrm{s}$, respectively. These minima fit well with the results presented in Figure 4 (arrows).
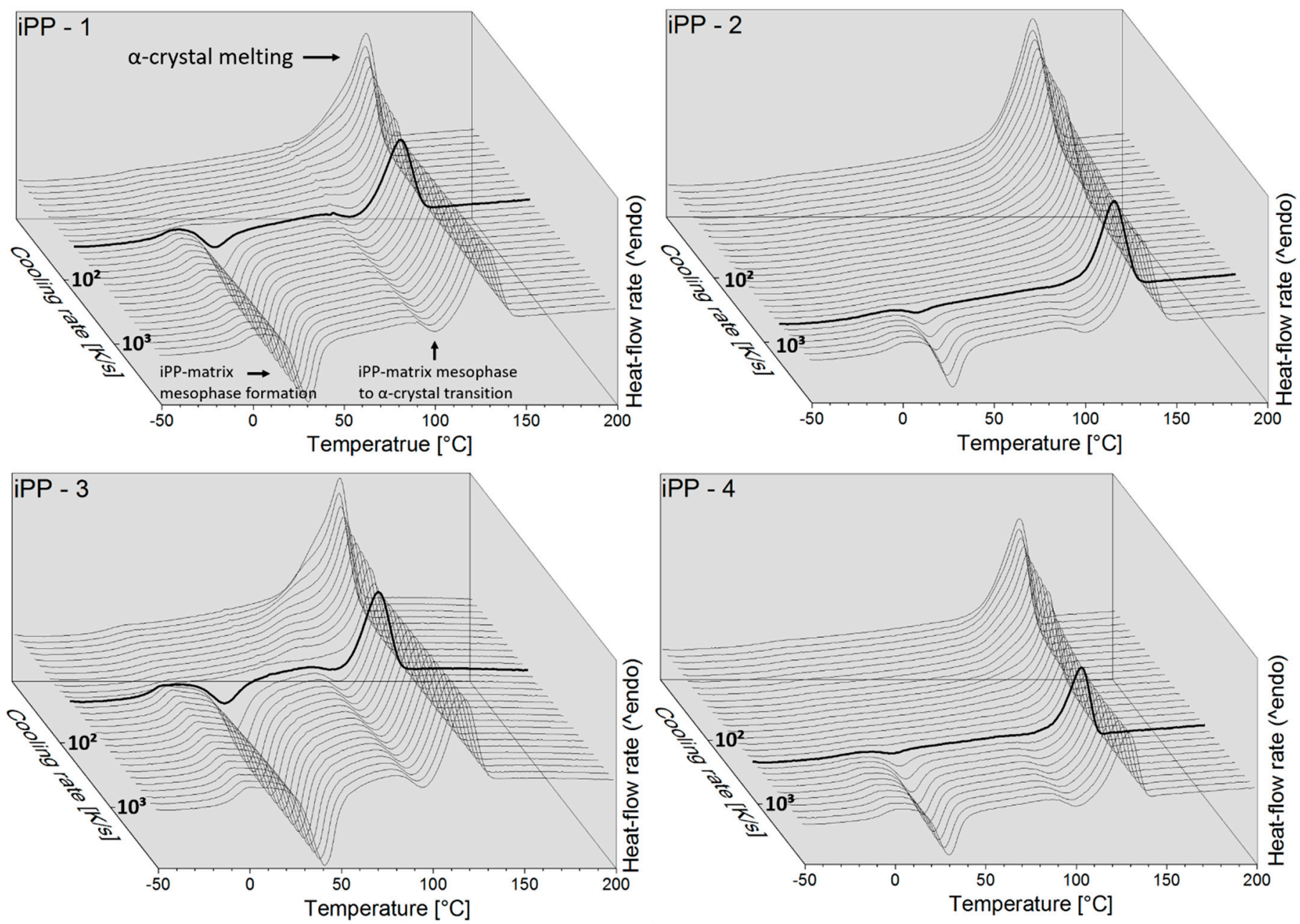

Figure 6. FSC heating curves after crystallizing at different cooling rates. The heating rate was set to $1000 \mathrm{~K} / \mathrm{s}$ and exothermic heat-flow is downwards.

Both the formation of the mesophase and the melting range of the $\alpha$-crystalline phase, are in the similar temperature range for all materials and are comparable to the literature [10]. The iPP-1 and iPP-3 grades exhibit a secondary melting peak after cooling at low rates at lower temperatures than the main melting peak. The low-temperature shoulder indicates melting of initially evident crystals and shifts to lower temperatures as the cooling rate increases until it ultimately disappears. The $\alpha$-crystal melting temperature is controlled by the prior transition of mesophase to $\alpha$-crystals, and is independent of cooling rate; it only depends on heating rate, which, however, is constant [48].

\subsection{Crystallization Rate as Function of Temperature}

In Figure 7, the typical bimodal temperature dependence of the crystallization rate is given. Just the non-nucleated RACO iPP-3 shows a trimodal shape, as reported in [45]. In the lower crystallization-temperature range, the formation of the mesophase can be clearly seen by its distinct and rather grade-independent kinetics, reported elsewhere [15,23,49-51]. 
However, in the case of the iPP-3, mesophase formation is much slower. In the hightemperature range, $\alpha$-crystallization takes place. The $\alpha$-crystallization of the nucleated grades iPP-2 and iPP-4 seems to be similar and starts earlier in comparison to the nonnucleated grades. In the case of iPP-2, crystallization already starts during cooling, which can be concluded from the results of the non-isothermal crystallization (Figure 4). There, it was shown that crystallization of iPP-2 is still possible up to cooling rates of $1500 \mathrm{~K} / \mathrm{s}$ and, therefore, there is a gap in between the determined values of meso- and $\alpha$-phase given in Figure 7. In the case of the non-nucleated HP iPP-1, the $\alpha$-phase formation is additionally shifted to higher temperatures. For the non-nucleated RACO iPP-3, the observations regarding the second heterophasic nucleation mechanism made by the non-isothermal analysis are confirmed by the results of the isothermal observations. The crystallization peak time shows a significant decrease when the temperature is lowered below $75{ }^{\circ} \mathrm{C}$, which is in the same temperature range shown in Figure 4 and is of the same order like discussed in [45]. The results of Figure 7 give also an explanation of non-detected mesophase formation in the case of iPP-2, iPP-3 and iPP-4. In all cases the maximum crystallization rate for $\alpha$-crystal formation is slightly faster or similar to the maximum rate in the low temperature range. Only when mesophase formation is significantly faster than crystallization at high temperature, as in the case of iPP-1, can it be detected in the non-isothermal analysis.

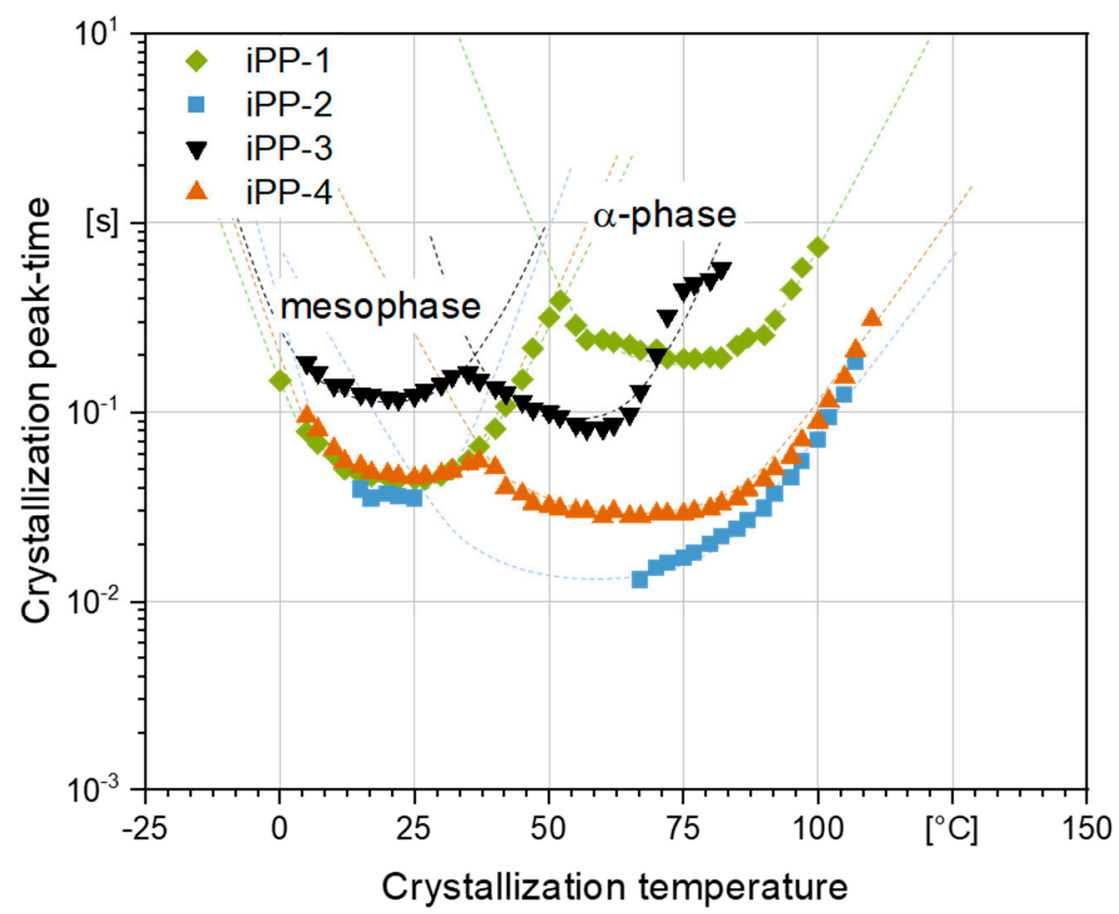

Figure 7. Isothermal crystallization peak-time depending on the crystallization temperature determined from the isothermal crystallization curves.

The influence of the crystallization temperature on the nucleation density and characteristic length-scale of the superstructure is determined from the micrographs given in Figure 8. The result of the optical investigation represents the effect of the thermal investigation of Figure 7. The iPP-1 has isolated crystalline structures at a crystallization temperature of $120^{\circ} \mathrm{C}$, which, according to their size, have grown slowly. If the material is crystallized at $110{ }^{\circ} \mathrm{C}$, the material appears perfectly fine-crystalline. If the holding temperature is set lower, it can be seen that the structures become smaller. At a temperature of $30^{\circ} \mathrm{C}$, no visible structures can be seen by the use of polarized light microscopy. According to Figure 7 in case of iPP-1, $\alpha$-crystallization is very slow and the replacement by the mesophase is in the range of $50^{\circ} \mathrm{C}$. If the temperature becomes lower, the crystallization is increasingly suppressed. Examining the micrographs in Figure 8, starting from sample 
iPP-1 downwards, it can be observed that in the case of nucleated iPP-2, the sample is already completely fine-crystalline at $120^{\circ} \mathrm{C}$. The fine, visible structures disappear on lowering the temperature. However, compared to iPP-1, a few finely distributed, small structures can still be seen at low temperatures of $30^{\circ} \mathrm{C}$. The non-nucleated copolymer iPP-3 does not exhibit any visible crystalline structures at $120^{\circ} \mathrm{C}$. At lower temperatures of $110^{\circ} \mathrm{C}$, the sample is completely fine-crystalline, like iPP-1. Comparing the samples iPP-1 and iPP-3 and looking at the results of the thermal analysis in Figure 7, it can be seen that iPP-3 crystallizes after a longer holding time and the $\alpha$-crystallization is shifted to lower temperatures. From the fine-crystalline structures it is concluded that iPP- 3 appears to exhibit a high nucleation density at 80 and $110^{\circ} \mathrm{C}$, that is, a temperature above the observed decrease in the crystallization peak time. At $50^{\circ} \mathrm{C}$ and lower, no crystalline structures are visible for iPP-3. The nucleated copolymer iPP-4 behaves similar to iPP-2, as is concluded from Figure 7.

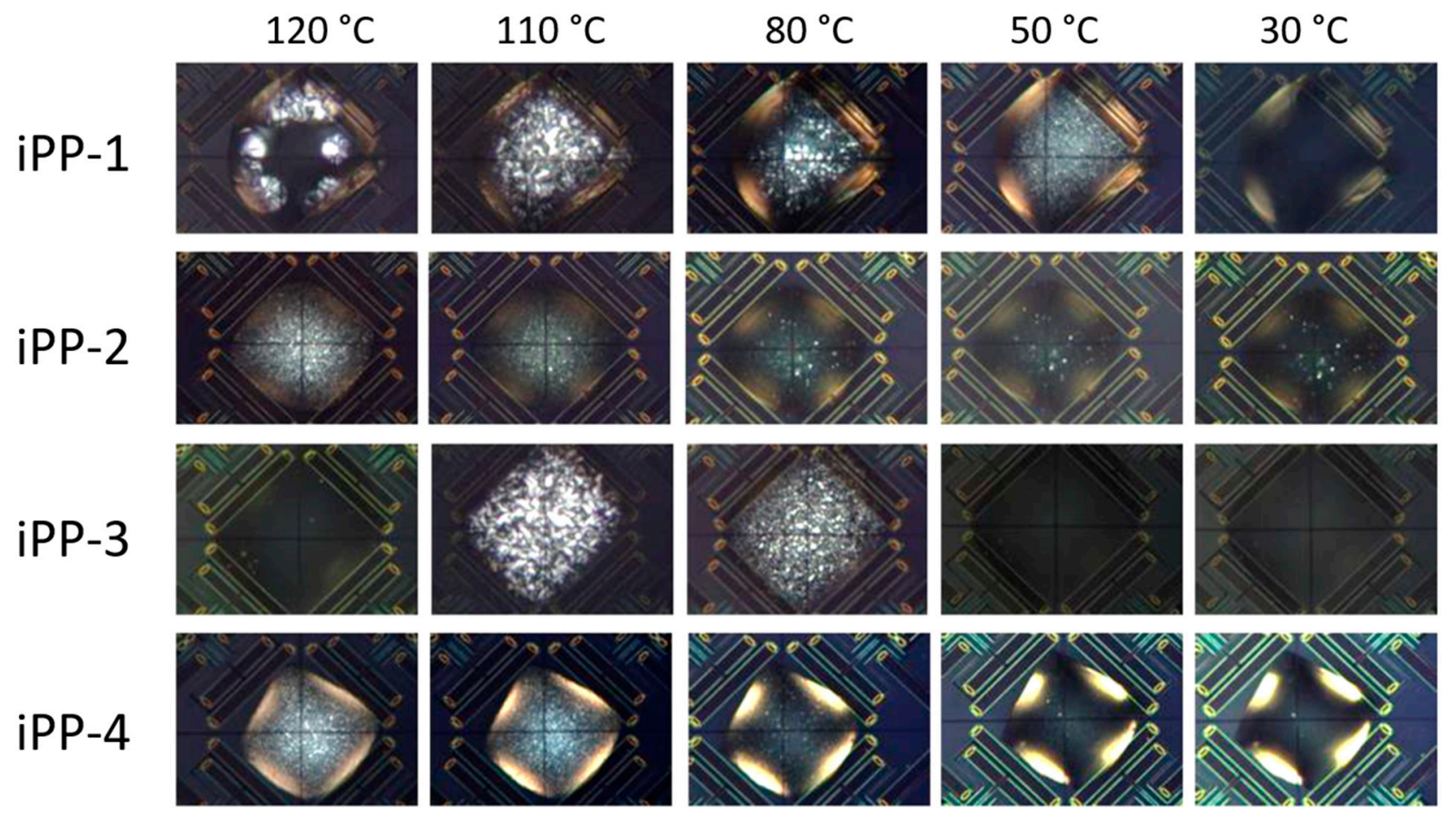

Figure 8. Micrographs of iPP homo- and copolymers at different isothermal crystallization temperatures analyzed by fast scanning chip calorimetry (FSC).

\section{Conclusions}

Based on the state of the art, four different iPP grades, with various molecular structures and nucleation additives, were investigated in the present work with respect to their pressure and thermal history-dependent crystallization behavior.

It is shown that the pressure and the cooling rate have an opposite influence on the crystallization temperature of the materials. While the crystallization temperature increases linearly with increasing pressure, it decreases with increasing cooling rate. The calculated pressure-dependent shift factor of the crystallization temperature is independent of the material. Comparison of the expansion coefficients suggests that the RACO and HECO appear to be sterically hindered in their crystallization by their comonomer units and are, therefore, not as densely packed as the HPs. The results of the FSC investigation allow conclusions to be drawn about $\alpha$ - and mesophase formation as a function of temperature and cooling rate. It has been shown that the addition of nucleating agents to the material has a significant effect on the maximum cooling rate at which the formation of $\alpha$-crystals is still possible. While the maximum cooling rate for the non-nucleated materials is about 
$100 \mathrm{~K} / \mathrm{s}$, it is $1000 \mathrm{~K} / \mathrm{s}$ for the nucleated materials. It also appears that the addition of nucleating agents compensates the effect of macromolecular structure on crystallization. For example, the non-nucleated materials HP and RACO show significant differences, while the nucleated materials HP and HECO show similar crystallization kinetics regardless of pressure or their thermal history and despite their different structure. The non-nucleated RACO showed a significant shift of the cooling rate-induced mesophase formation to higher temperatures, and the temperature-dependent crystallization rate of $\alpha$ - and mesophase was much slower than compared to the non-nucleated HP. Moreover, in the case of the RACO and HECO copolymers, a second nucleation mechanism could be detected. Such a mechanism has already been demonstrated for other iPP grades [45-47]. According to [46], this could be due to the activation of additional heterogeneous nuclei, and requires further investigation.

Author Contributions: Conceptualization, Y.S. and I.K.; methodology, Y.S. and R.A.; investigation, Y.S. and R.A.; writing — original draft preparation, Y.S.; writing—review and editing, R.B. and R.A.; visualization, Y.S. and R.B.; supervision, I.K.; project administration, I.K. All authors have read and agreed to the published version of the manuscript.

Funding: The authors thank the Dutch Polymer Institute (DPI) for financial support. This research forms part of the DPI program, project \#816t18.

Acknowledgments: The authors thanks the industrial partners of Borealis AG, Braskem Europe $\mathrm{GmbH}$ and SABIC for their support.

Conflicts of Interest: The authors declare no conflict of interest.

\section{References}

1. Addink, E.J.; Beintema, J. Polymorphism of crystalline polypropylene. Polymer 1961, 2, 185-193. [CrossRef]

2. Jones, A.T.; Aizlewood, J.M.; Beckett, D.R. Crystalline forms of isotactic polypropylene. Makromol. Chem. 1964, 75, 134-158. [CrossRef]

3. Natta, G.; Corradini, P. Structure and Properties of Isotactic Polypropylene. Nuovo Cim. 1960, 15, 12. [CrossRef]

4. Auriemma, F.; de Ballesteros, O.R.; De Rosa, C.; Corradini, P. Structural disorder in the alpha form of isotactic polypropylene. Macromolecules 2000, 33, 8764-8774. [CrossRef]

5. Keith, H.D.; Padden, F.J.; Walter, N.M.; Wyckoff, H.W. Evidence for a second crystal form of polypropylene. J. Appl. Phys. 1959, 30, 1485-1488. [CrossRef]

6. Padden, F.J.; Keith, H.D. Spherulitic crystallization in polypropylene. J. Appl. Phys. 1959, 30, 1479-1484. [CrossRef]

7. Turnerjones, A. Development of gamma-crystal form in random copolymers of propylene and their analysis by dsc and X-ray methods. Polymer 1971, 12, 487-508. [CrossRef]

8. Zia, Q.; Radusch, H.J.; Androsch, R. Deformation behavior of isotactic polypropylene crystallized via a mesophase. Polym. Bull. 2009, 63, 755-771. [CrossRef]

9. Zia, Q.; Androsch, R.; Radusch, H.J. Effect of the Structure at the Micrometer and Nanometer Scales on the Light Transmission of Isotactic Polypropylene. J. Appl. Polym. Sci. 2010, 117, 1013-1020. [CrossRef]

10. Mileva, D.; Wang, J.B.; Gahleitner, M.; Jariyavidyanont, K.; Androsch, R. New Insights into Crystallization of Heterophasic Isotactic Polypropylene by Fast Scanning Chip Calorimetry. Polymers 2020, 12, 1683. [CrossRef]

11. Gahleitner, M.; Bachner, C.; Ratajski, E.; Rohaczek, G.; Neissl, W. Effects of the catalyst system on the crystallization of polypropylene. J. Appl. Polym. Sci. 1999, 73, 2507-2515. [CrossRef]

12. Gahleitner, M.; Jaaskelainen, P.; Ratajski, E.; Paulik, C.; Reussner, J.; Wolfschwenger, J.; Neissl, W. Propylene-ethylene random copolymers: Comonomer effects on crystallinity and application properties. J. Appl. Polym. Sci. 2005, 95, 1073-1081. [CrossRef]

13. Laihonen, S.; Gedde, U.W.; Werner, P.E.; Westdahl, M.; Jaaskelainen, P.; MartinezSalazar, J. Crystal structure and morphology of melt-crystalized poly(propylene-stat-ethylene) fractions. Polymer 1997, 38, 371-377. [CrossRef]

14. Laihonen, S.; Gedde, U.W.; Werner, P.E.; MartinezSalazar, J. Crystallization kinetics and morphology of poly(propylene-statethylene) fractions. Polymer 1997, 38, 361-369. [CrossRef]

15. Cavallo, D.; Gardella, L.; Alfonso, G.C.; Mileva, D.; Androsch, R. Effect of comonomer partitioning on the kinetics of mesophase formation in random copolymers of propene and higher alpha-olefins. Polymer 2012, 53, 4429-4437. [CrossRef]

16. Chen, J.Y.; Cao, Y.; Kang, J.A.; Li, H.L. Effect of Temperature and Comonomer Content on Thermal Behavior and Crystallization Property of the Propylene-Ethylene Random Copolymers. J. Macromol. Sci. Part B 2011, 50, 248-265. [CrossRef]

17. Yokoyama, Y.; Ricco, T. Crystallization and morphology of reactor-made blends of isotactic polypropylene and ethylene-propylene rubber. J. Appl. Polym. Sci. 1997, 66, 1007-1014. [CrossRef] 
18. Doshev, P.; Lohse, G.; Henning, S.; Krumova, M.; Heuvelsland, A.; Michler, G.; Radusch, H.J. Phase interactions and structure evolution of heterophasic ethylene-propylene copolymers as a function of system composition. J. Appl. Polym. Sci. 2006, 101, 2825-2837. [CrossRef]

19. Gahleitner, M.; Tranninger, C.; Doshev, P. Heterophasic copolymers of polypropylene: Development, design principles, and future challenges. J. Appl. Polym. Sci. 2013, 130, 3028-3037. [CrossRef]

20. Cavallo, D.; Azzurri, F.; Floris, R.; Alfonso, G.C.; Balzano, L.; Peters, G.W. Continuous Cooling Curves Diagrams of Propene/Ethylene Random Copolymers. The Role of Ethylene Counits in Mesophase Development. Macromolecules 2010, 43, 2890-2896. [CrossRef]

21. Schick, C.; Androsch, R. Nucleation-controlled semicrystalline morphology of bulk polymers. Polym. Cryst. 2018, 1, 15. [CrossRef]

22. Foresta, T.; Piccarolo, S.; Goldbeck-Wood, G. Competition between alpha and gamma phases in isotactic polypropylene: Effects of ethylene content and nucleating agents at different cooling rates. Polymer 2001, 42, 1167-1176. [CrossRef]

23. De Santis, F.; Adamovsky, S.; Titomanlio, G.; Schick, C. Isothermal nanocalorimetry of isotactic polypropylene. Macromolecules 2007, 40, 9026-9031. [CrossRef]

24. De Santis, F.; Adamovsky, S.; Titomanlio, G.; Schick, C. Scanning nanocalorimetry at high cooling rate of isotactic polypropylene. Macromolecules 2006, 39, 2562-2567. [CrossRef]

25. Mileva, D.; Androsch, R.; Cavallo, D.; Alfonso, G.C. Structure formation of random isotactic copolymers of propylene and 1-hexene or 1-octene at rapid cooling. Eur. Polym. J. 2012, 48, 1082-1092. [CrossRef]

26. Mileva, D.; Androsch, R. Effect of co-unit type in random propylene copolymers on the kinetics of mesophase formation and crystallization. Colloid Polym. Sci. 2012, 290, 465-471. [CrossRef]

27. Mileva, D.; Wang, J.B.; Gahleitner, M.; Doshev, P.; Androsch, R. Crystallization behaviour of heterophasic propylene-ethylene copolymer at rapid cooling conditions. Polymer 2016, 102, 214-220. [CrossRef]

28. Forstner, R.; Peters, G.W.M.; Meijer, H.E.H. A Novel Dilatometer for PVT Measurements of Polymers at High Cooling-And Shear Rates. Int. Polym. Process. 2009, 24, 114-121. [CrossRef]

29. van Drongelen, M.; Roozemond, P.C.; Peters, G.W.M. Non-isothermal Crystallization of Semi-Crystalline Polymers: The Influence of Cooling Rate and Pressure. In Polymer Crystallization Ii: From Chain Microstructure to Processing; Auriemma, F., Alfonso, G.C., DeRosa, C., Eds.; Springer: Berlin, Germany, 2017; Volume 277, pp. 207-242. [CrossRef]

30. van Drongelen, M.; van Erp, T.B.; Peters, G.W.M. Quantification of non-isothermal, multi-phase crystallization of isotactic polypropylene: The influence of cooling rate and pressure. Polymer 2012, 53, 4758-4769. [CrossRef]

31. Van der Beek, M.H.E.; Peters, G.W.M.; Meijer, H.E.H. The influence of cooling rate on the specific volume of isotactic poly(propylene) at elevated pressures. Macromol. Mater. Eng. 2005, 290, 443-455. [CrossRef]

32. Zuidema, H.; Peters, G.W.M.; Meijer, H.E.H. Influence of cooling rate on pVT-data of semicrystalline polymers. J. Appl. Polym. Sci. 2001, 82, 1170-1186. [CrossRef]

33. Karl, V.H.; Asmussen, F.; Ueberreiter, K. Pressure-dependence of viscoelastic and physicochemical properties of polymers.1. description of a high-pressure dilatometer and some applications. Angew. Makromol. Chem. 1977, 62, 145-161. [CrossRef]

34. Karl, V.H.; Asmussen, F.; Ueberreiter, K. Pressure-dependence of viscoelastic and physicochemical properties of polymers.4. isothermic and nonisothermic crystallization. Eur. Polym. J. 1977, 13, 1025-1031. [CrossRef]

35. Zhang, L.; Van Drongelen, M.; Alfonso, G.C.; Peters, G.W.M. The effect of pressure pulses on isotactic polypropylene crystallization. Eur. Polym. J. 2015, 71, 185-195. [CrossRef]

36. Bruckner, S.; Phillips, P.J.; Mezghani, K.; Meille, S.V. On the crystallization of gamma-isotactic polypropylene: A high pressure study. Macromol. Rapid Commun. 1997, 18, 1-7. [CrossRef]

37. Schick, C.; Mathot, V. Fast Scanning Calorimetry, 1st ed.; Springer International Publishing AG: Cham, Switzerland, 2016 ; pp. 6-13. [CrossRef]

38. Wang, J.; Hopmann, C.; Schmitz, M.; Hohlweck, T.; Wipperfurth, J. Modeling of pvT behavior of semi-crystalline polymer based on the two-domain Tait equation of state for injection molding. Mater. Des. 2019, 13, 10. [CrossRef]

39. He, J.; Zoller, P. Crystallization of polypropylene, nylon-66 and poly(ethylene-terephthalate) at pressures to $200 \mathrm{mpa}-\mathrm{Kinetics}$ and characterization of products. J. Polym. Sci. Part B-Polym. Phys. 1994, 32, 1049-1067. [CrossRef]

40. Sorrentino, A.; Pantani, R. Determination of the effect of pressure on viscosity of an isotactic polypropylene. Polym. Bull. 2013, 70, 2005-2014. [CrossRef]

41. Luye, J.F.; Regnier, G.; Le Bot, P.; Delaunay, D.; Fulchiron, R. PVT measurement methodology for semicrystalline polymers to simulate injection-molding process. J. Appl. Polym. Sci. 2001, 79, 302-311. [CrossRef]

42. Nakafuku, C. High-pressure dta study on the melting and crystallization of isotactic polypropylene. Polymer 1981, 22, 1673-1676. [CrossRef]

43. Leute, U.; Dollhopf, W.; Liska, E. Dilatometric study on melting of polypropylene at elevated pressure. Colloid Polym. Sci. 1978, 256, 914-922. [CrossRef]

44. Gahleitner, M.; Mileva, D.; Gloger, D.; Androsch, R.; Tranchida, D. Polymer Structure Effects on Crystallization and Properties in Polypropylene Film Casting. In Proceedings of Pps-32: The 32nd International Conference of the Polymer Processing Society; Maazouz, A., Ed.; American Institute of Physics: Melville, NY, USA, 2017; p. 1914. [CrossRef]

45. Androsch, R.; Monami, A.; Kucera, J. Effect of an alpha-phase nucleating agent on the crystallization kinetics of a propylene/ethylene random copolymer at largely different supercoiling. J. Cryst. Growth 2014, 408, 91-96. [CrossRef] 
46. Schawe, J.E.K.; Vermeulen, P.A.; van Drongelen, M. Two processes of alpha-phase formation in polypropylene at high supercoiling. Thermochim. Acta 2015, 616, 87-91. [CrossRef]

47. Cai, J.; Luo, R.Q.; Lv, R.H.; He, Y.C.; Zhou, D.S.; Hu, W.B. Crystallization kinetics of ethylene-co-propylene rubber/isotactic polypropylene blend investigated via chip-calorimeter measurement. Eur. Polym. J. 2017, 96, 79-86. [CrossRef]

48. Mileva, D.; Androsch, R.; Zhuravlev, E.; Schick, C. Temperature of Melting of the Mesophase of Isotactic Polypropylene Macromolecules 2009, 42, 7275-7278. [CrossRef]

49. Silvestre, C.; Cimmino, S.; Duraccio, D.; Schick, C. Isothermal crystallization of isotactic poly(propylene) studied by superfast calorimetry. Macromol. Rapid Commun. 2007, 28, 875-881. [CrossRef]

50. Androsch, R.; Di Lorenzo, M.L.; Schick, C.; Wunderlich, B. Mesophases in polyethylene, polypropylene, and poly(1-butene). Polymer 2010, 51, 4639-4662. [CrossRef]

51. Mileva, D.; Androsch, R.; Zhuravlev, E.; Schick, C.; Wunderlich, B. Formation and Reorganization of the Mesophase of Isotactic Polypropylene. Mol. Cryst. Liq. Cryst. 2012, 556, 74-83. [CrossRef] 